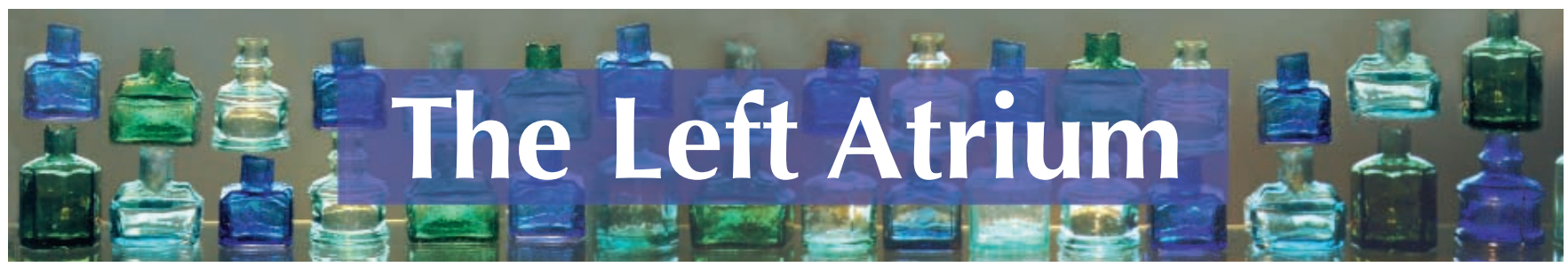

\section{Photographs at war}

Regarding the pain of others

Susan Sontag

New York: Picador / Farrar, Straus and Giroux; 2003

\$16 (paper) 131 pp ISBN 0-312-42219-9

$\mathrm{T}$ he US-led war and occupation in Iraq has produced many surprises - the absence of weapons of mass destruction (even the absence of much of an army), Saddam Hussein alone in a spider hole, and, in a war with religious undertones (we're more moral than you, God's on our side) some abhorrent photographs of prisoner abuse by US soldiers. Although published before the Abu Ghraib photographs were splashed across the Internet, Sontag's recent book helps place these images in sobering perspective.

Sontag opens her critical analysis of images of suffering as a result of war or torture by reminding us of Virginia Woolf's feminist polemic The Three Guineas, which begins as a response to a question posed by an eminent (but probably fictional) male lawyer who has sought her feminine response to the question, "How in your opinion are we to prevent war?" Woolf begins by considering photographs of the Spanish Civil War that were daily appearing in newspapers in London in 1936-1937:

This morning's collection contains the photograph of what might be a man's body, or a woman's; it is so mutilated that it might, on the other hand, be the body of a pig. But those certainly are dead children, and that undoubtedly is the section of a house. ... These photographs are not an argument; they are simply a crude statement of fact addressed to the eye.

There is no doubt, Sontag agrees, that photographic images are "a means of making 'real' (or 'more real') matters the privileged and the merely safe might prefer to ignore." But the re- sponse to apparently evidentiary photographs is more complex than that, as Sontag shows, and there is no guarantee, as Woolf had hoped, of their humanizing effect. War photographs can be disputed with "the standard response ... that they are a fabrication, that no such atrocity ever took place"; similarly, their documentary purposes are not innocent. Because photographs must be "framed" by the person making the image and selected from a vast array of other possible images, they imply a point of view. Much weight is given to the factual claims made in a caption, which might identify dead or mutilated children, women or combatants as Arabs or Jews, Serbs or Croats, terrorists or martyrs sometimes using the same image. Writing and reporting also involve constraints of medium, editorial controls, and conflicts of interests, beliefs and values, with the same propensity for distortion. But photographs convey an often unwarranted sense of "reality" or "truth" that far surpasses the written report.

In this essay Sontag devotes a chapter to the "long pedigree" of the visual depiction of atrocities: Goya's etchings of Napoleon's soldiers killing Spanish civilians; the first war photographs, taken by Roger Fenton in the Crimea; the American Civil War photographs, which were perhaps the first to depict dead soldiers (although, given the slow technology of photography at the time, most were staged); the iconography of the Second World War (the "reconstructed" raising of the American flag on Iwo Jima); and the "signature Vietnam War horror-photograph from 1972, taken by Huynh Cong Ut, of children from a village that has just been doused with American napalm, running down the highway, shrieking with pain" - a photograph that could not have been posed, and to which many ascribe a catalytic effect in the eventual American decision to pull out of Vietnam. Even though no photographs are reprinted with Sontag's essay, many readers will be able to "see" some of these images. They remain etched in memory, unlike the details of

Walter Cronkite's distinctively intoned nightly reports on the progress of the war.

The US photographs and presumably the still-

to-be-released videos of prisoner torture and abuse in Abu Ghraib are but the latest in the long lineage of war photographs. Let's assume for the moment that they are "real" (not entirely posed, and not fabricated by the "enemy"). Photographs of actual combat and war are usually taken by photographers and, if not commissioned by the war propaganda offices, are certainly screened by them whenever possible. There have been few examples of combat photographs actually taken by soldiers. In Vietnam, some American soldiers took pictures, but these have only recently been shown to the public - partly because of ambivalent feelings about the war.

What would Sontag have to say about the Abu Ghraib images? We have entered a new era in which combatants are armed with digital cameras along with high-powered weapons and other more conventional instruments of 
war. Likely a first in war photography, the Abu Ghraib photographs are incriminating documents staged and recorded by US soldiers, men and women. Their release, first to a military investigator and then to the public, has had an effect more profound than any official photographic documentation of this war.

Sontag, when she writes about these images, will undoubtedly probe the soldiers' motives for taking these pictures. Unlike previous war images, these photographs cannot be attributed to propaganda, nor to an intention to accurately document the effects of war (although they do that most disturbingly). Boredom, amusement or trophy-collection (much like taking weapons or ensignia from captured or dead enemy combatants) may be the motive. But there is also an underlying motive of hatred and revenge.

Sontag, commenting on photographs of black victims being lynched in the 1890s and 1930s, writes that seeing these pictures (in an exhibition in New York in 2000) "should help us understand such atrocities not as the acts of 'barbarians' but as the reflections of a belief system, racism, that by defining one people as less human than another legitimates torture and murder." She then adds, "But maybe they were barbarians. Maybe this is what most barbarians look like. (They look like everybody else.)"

In one of the Abu Ghraib prison photographs, US army private Lynndie England is seen holding the end of a dog leash attached to the neck of a naked Iraqi soldier on his knees. In oth- ers she stands and points, grinning, at the genitals of naked prisoners. What is so disturbing about these images is that they appear to have been taken for amusement, an amusement generated by a complete disrespect that one might describe as racist. And they are disturbing because England and the other participants look so ordinary.

Regarding the Pain of Others is a fascinating exploration that complements and expands on Sontag's earlier work, On Photograpby. This is the Sontag we expect, admire and even revere: critical, thoughtful, insightful, thoroughly wideranging in her sources and ideas and always penetrating and disturbing.

\section{John Hoey}

Editor

CMA7

\section{Lifeworks}

\section{Self-portraits of illness: the gift of the gaze}

One of our projects at the Centre for Global eHealth Innovation is to collaborate with people with colorectal cancer as they represent their experiences through visual and text-based narratives. Participants are provided with cameras and asked to photograph whatever they feel would represent aspects of their experience of living with colorectal cancer. In this article we discuss photographic self-portraits taken, with the assistance of a friend, by a 78-year-old woman who has since passed away. Composing the photographs in a way that retained some anonymity, she consented to their wide dissemination in the hope of helping others to overcome feelings of being alone in living with cancer.

$66 \bigcirc$ hy! I look like a little old grandmother!" she laughed when she brought the pictures out for us to look at. "I never was the most bashful person; I used to run naked as a child."

We sat together in comfortable silence for several moments before she spoke again. "Bathing is soothing. I put sachets of camomile in my bath; it's good for the stoma."

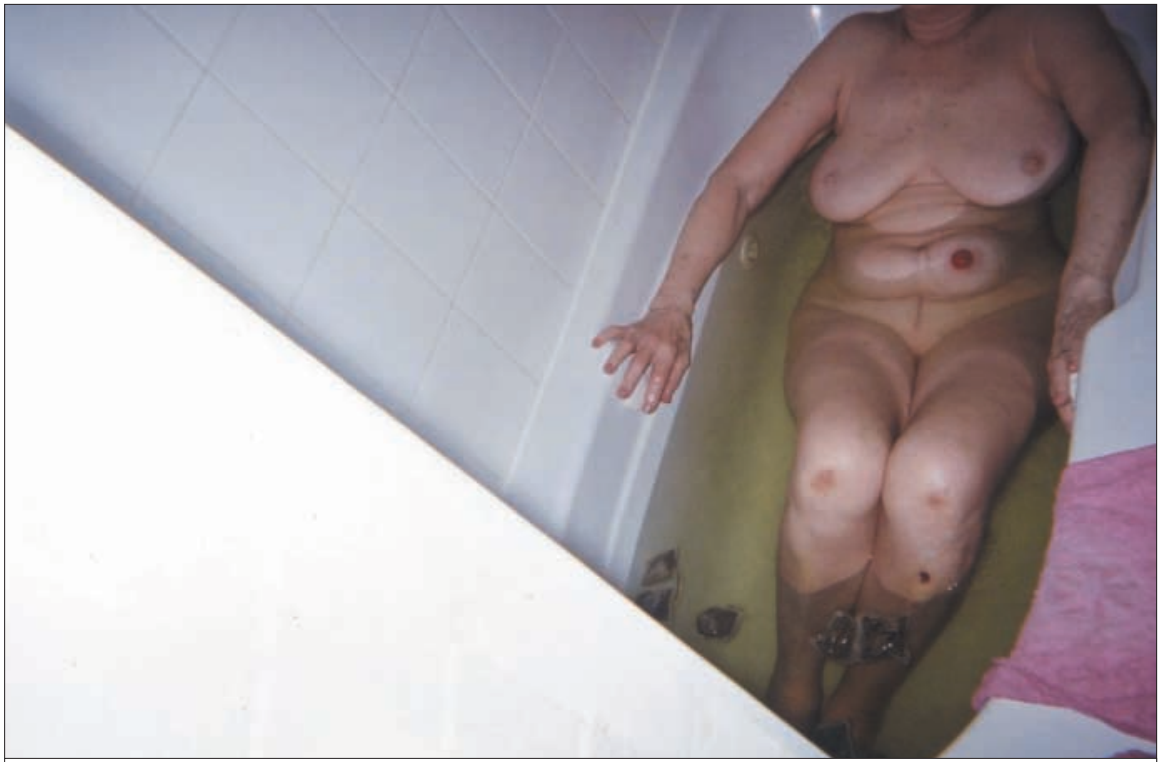

A camomile bath.

She carefully placed the photograph face down on the table and went on to another, saying as she did so, "But you know, I thought it would help others, let them know they are not alone."

This last statement provides us with her motivation. We never had the opportunity to discuss her own experience of loneliness in illness, but we know that she spoke strongly about the crucial role of support. She recounted that before her surgery she had tried to find 